NASZA DERMATOLOGIA Onlin OUR DERMATOLOGY Online Nil

Competing Interests: None

\section{REVERSIBLE HYPOPIGMENTATION OF HAIR SECONDARY TO VITAMIN B12 DEFICIENCY}

\author{
Ramesh Y Bhat, Chaitanya Varma
}

Department of Pediatrics, Kasturba Medical College, Manipal, Karnataka, India

Corresponding author: Dr. Chaitanya Varma
Sir

Vitamin B12 deficiency affects all age groups and involves hematological gastrointestinal and central nervous systems. Mucocutaneous manifestations are rare, especially in children. We present a child with reversible hypopigmentation of hair because of vitamin B12 deficiency. A 3 year old male child born of third degree consanguineous marriage presented with history of lethargy, and increasing hyperpigmentation over the knuckles and feet. On examination child was observed to have pallor, sparse lusterless hypopigmented hair (Fig. 1, 2), angular stomatitis and hyperpigmentation over the hands and feet. Anthropometry was normal for age. Systemic examination was normal. Blood counts showed a low hemoglobin $(10 \mathrm{gm} /$ dl), a reticulocyte count of 3\% with the peripheral smear showing macrocytes (Mean cell volume, MCV=120fl) and anisopoikilocytosis. Bone marrow aspirate showed hyperplastic marrow with features of megaloblastic anemia. Serum electrolyte levels were normal. Serum vitamin B12 level was low $(109.7 \mathrm{pg} / \mathrm{ml})$ and Folate level was normal $(20 \mathrm{Mcg} / \mathrm{ml})$. Child was given a single dose of Vitamin B12 injection (1000microgram) followed by 1000 micrograms of oral Vitamin B12 daily. Since the child was a vegetarian a diet rich in Vitamin B12 was also adviced. On follow up child showed remarkable improvement in general condition, was active, playful and interactive. Pallor had disappeared and the hyperpigmentation over the limbs had significantly lightened. The hypopigmented hair had been replaced with dark healthy hair. The blood picture showed normalizing of hemoglobin levels with a good reticulocyte response.

Skin hyper pigmentation, vitiligo, angular stomatitis, and hair changes are some of the muco cutaneous manifestations associated with vitamin B12 deficiency [1]. A study done by Aaron et al. reported that $19 \%$ of the patients with Vitamin B12 deficiency had skin hyperpigmentation but only $9 \%$ of them had hair changes [2]. Reversible hypopigmentation of hair in the pediatric age group due to Vitamin B12 deficiency has very rarely been reported in medical literature unlike reversible hyperpigmentation of skin [3,4]. Unresolving pigmentation of the skin or hypopigmentation of hair should make the treating pediatrician consider treatment with Vitamin B12.

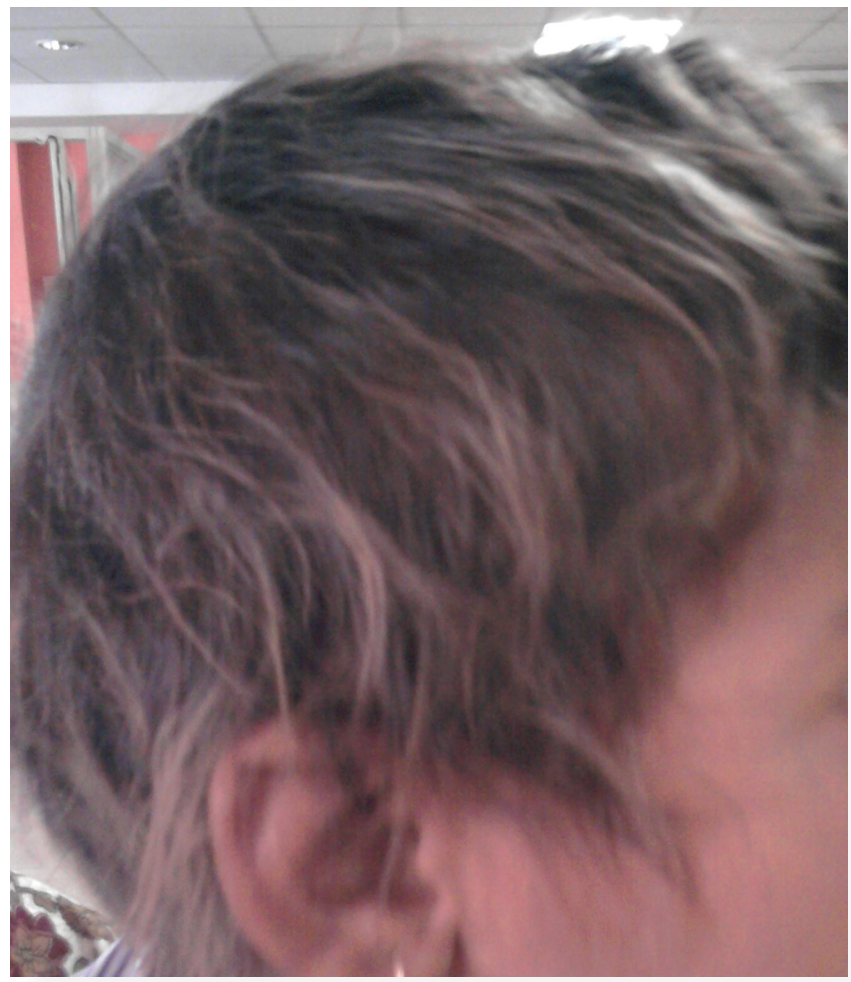

Figure 1. Sparse hypopigmented hair 


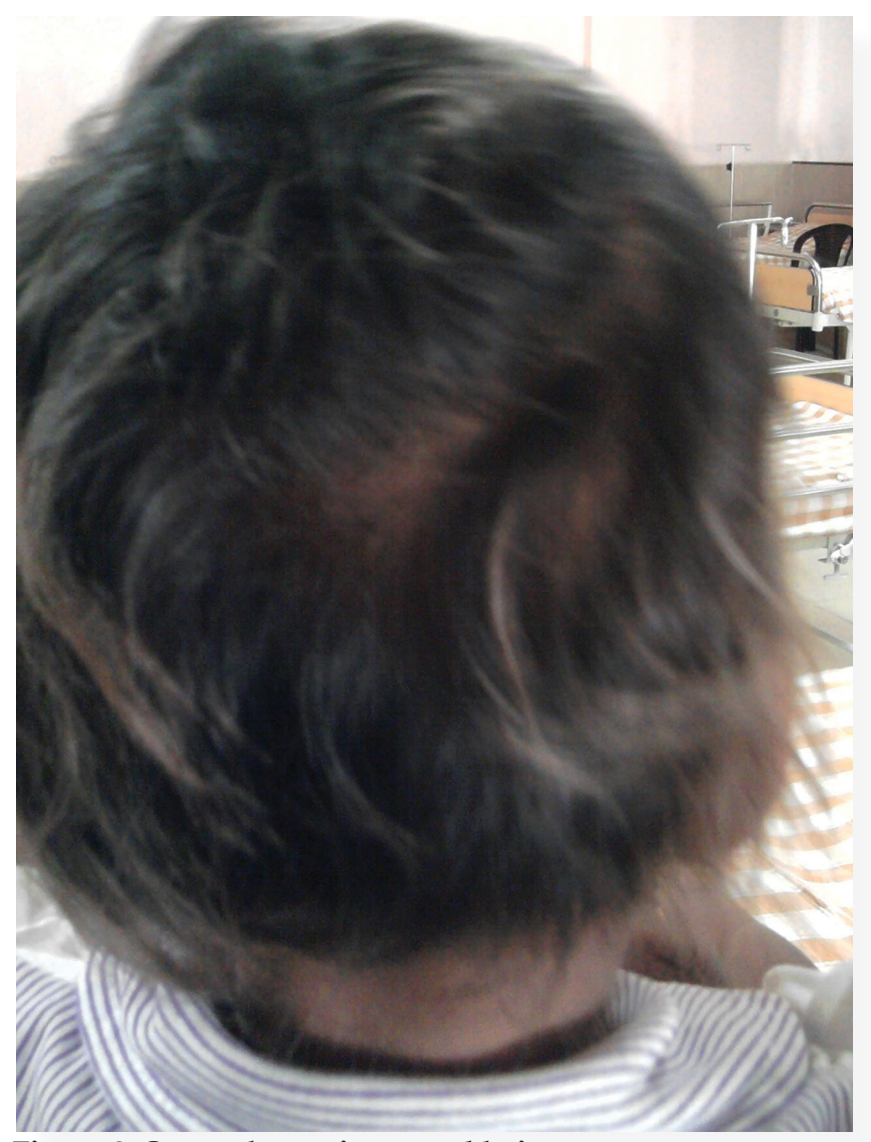

Figure 2. Sparse hypopigmented hair

\section{REFERENCES}

1. Mori K, Ando I, Kukita A: Generalized hyperpigmentation of the skin due to vitamin B12 deficiency. J Dermatol. 2001;28:282-5.

2.Aaron S, Kumar S, Vijayan J, Jacob J, Alexander M, Gnanamuthu $\mathrm{C}$ : Clinical and laboratory features and response to treatment in patients presenting with vitamin B12 deficiency-related neurological syndromes. Neurol India. 2005;53:55-8.

3. Hoffman CF, Palmer DM, Papadopoulos D: Vitamin B12 deficiency: a case report of ongoing cutaneous hyperpigmentation. Cutis. 2003;71:127-30.

4. Noppakun N, Swasdikul D: Reversible hyperpigmentation of skin and nails with white hair due to vitamin B12 deficiency. Arch Dermatol. 1986;122:896-9.

Copyright by Ramesh Y Bhat, et al. This is an open access article distributed under the terms of the Creative Commons Attribution License, which permits unrestricted use, distribution, and reproduction in any medium, provided the original author and source are credited. 